\title{
PERCEPÇÕES E LIMITES DO FAZER CIENTÍFICO: O CASO DA IMPERIAL COMISSÃO CIENTÍFICA DE EXPLORAÇÃO (1859-1861)
}

\author{
PERCEPTIONS AND LIMITATIONS OF SCIENTIFIC WORK : THE \\ CASE OF IMPERIAL SCIENTIFIC EXPLORATION COMMISSION (1859- \\ 1861)
}

DOI: http://dx.doi.org/10.15448/2178-3748.2015.2.21902

\author{
Karoline Viana Teixeira ${ }^{1}$ \\ Doutoranda em História Social - Universidade Federal do Ceará \\ karolineteixeira@gmail.com
}

\begin{abstract}
RESUMO: Considerada a primeira viagem científica composta exclusivamente por naturalistas brasileiros, a Comissão Científica de Exploração refletia o esforço do Império brasileiro na promoção de descobertas que viessem a alavancar a economia do país, como ocorria nas nações europeias do século XIX. A despeito das críticas, escassez de verbas e desavenças que minaram a continuidade dos seus trabalhos, gostaria de abordar aqui a experiência da Comissão Científica dentro das possibilidades e limites no uso da ciência como braço intelectual do desenvolvimento do Império brasileiro, num país que buscava lidar com a herança colonial e, ao mesmo tempo, estabelecer-se como nação moderna e civilizada, capaz de empreender o conhecimento de seu próprio território.
\end{abstract}

PALAVRAS-CHAVE: Ciência, história, viagem

ABSTRACT: Considered the first scientific journey composed exclusively of Brazilian naturalists, the Scientific Exploration Commission reflected the Brazilian Empire's effort in promoting discoveries that were to boost the country's economy, as occurred in European nations in the nineteenth century. Despite the criticism, shortage of funds and disagreements that have undermined the continuity of its work, I should like to address the experience of the Scientific Committee within the possibilities and limits on the use of science as an intellectual arm of the development of the Brazilian Empire, a country seeking deal with the colonial heritage and, at the same time, trying to establish itself as modern and civilized nation, able to take the knowledge of their own territory.

KEYWORDS: Science, history, travel.

No discurso proferido na sessão do Instituto Histórico e Geográfico Brasileiro (IHGB) de 30 de maio de 1856, o zoólogo Manoel Ferreira Lagos dirige-se ao imperador Pedro II e exorta-o sobre a necessidade de o governo "nomear uma comissão de engenheiros e naturalistas nacionais para explorar algumas das províncias menos conhecidas do Brasil”. Lagos justifica tal necessidade ao questionar os resultados da viagem do naturalista Francis de la Porte, conde de Castelnau, às regiões centrais da América do Sul, e aproveita para dar conta de um sem número de imprecisões e equívocos cometidos por viajantes e naturalistas estrangeiros que aqui estiveram, censurando-os num tom "ora demasiado sarcástico, ora facêto". Já era tempo,

\footnotetext{
${ }^{1}$ Este artigo conta com financiamento do Programa de Orientação em Operacionalização da Pós-Graduação Articulada à Graduação (Propag).
} 
segundo Lagos, não apenas de desmentir o exame feito por viajantes de má-fé ou levianos. Dever-se-ia mostrar que aqui não nos faltavam pessoas de talento e com as habilitações necessárias para a pesquisa científica (BRAGA, 1962, p. 16-17).

O episódio foi consagrado pela historiografia como prelúdio da Imperial Comissão Científica de Exploração das Províncias do Norte, realizada entre 1859 e 1861. Considerada a primeira viagem científica composta exclusivamente por brasileiros, a Comissão Científica reuniu alguns dos intelectuais e naturalistas mais renomados da época, tendo como área de exploração a província do Ceará, partes de Pernambuco, Piauí e Rio Grande do Norte, além da região do Rio Negro - esta empreendida por iniciativa particular por um de seus membros. Francisco Freire Alemão, Guilherme Schüch de Capanema, Giacomo Raja Gabaglia, Antonio Gonçalves Dias, além do próprio Ferreira Lagos, propositor da viagem exploratória, empreenderam um amplo trabalho de identificação e prospecção de recursos naturais, localização astronômica e geográfica, comércio, agricultura, pecuária, estado de vilas e cidades e condições das tribos indígenas.

Os chefes de seção escolhidos para a empreitada eram participantes ativos de uma comunidade acadêmica que vinha se estabelecendo no país ao longo do século XIX, apoiada em redes institucionais de ensino, pesquisa, belas-artes e formação de coleções arqueológicas e do mundo natural. Instituições como os já citados IHGB e Museu Nacional (para onde seriam destinadas as coleções de plantas, animais, minerais e outros artefatos), e outras como a Academia Imperial de Belas Artes, as Faculdades de Medicina, o Colégio Pedro II, a Escola Central, eram abertas e/ou mantidas pelo mecenato do governo, num processo iniciado com a instalação da Corte joanina na colônia americana e seguida após a independência por seus descendentes, Pedro I e Pedro II. Por seu turno, tal política de fomento era associada ao estabelecimento de novas nações e nacionalismos no cenário mundial, tanto na Europa quanto nas antigas regiões coloniais, tendo na história natural um braço estratégico importante para reforçar a posse de novos territórios e para a descoberta de materiais e técnicas que ampliassem os ganhos na Revolução Industrial em curso.

Mas por uma série de fatores políticos e financeiros, rivalidades internas e questionamentos via imprensa sobre a utilidade do projeto, apenas parte dos resultados da pesquisa de campo foi publicada. Os produtos trazidos no retorno à Corte foram objeto de várias exposições públicas, tendo sido incluídos na mostra de produtos nacionais levada para a Exposição Universal de 1862, em Londres. Já as coleções trazidas pelos “científicos” ajudaram a incrementar o acervo do Museu Nacional, além de fomentar pesquisas ulteriores. Apesar disso, o episódio é ainda referenciado por muitos autores pela ênfase nos episódios pitorescos, como a 
importação de 14 camelos da Argélia para fazer a travessia pelos sertões, boatos sobre badernas e seduções protagonizadas por Guilherme Capanema e Gonçalves Dias, além da perda de vasto material da Seção Geológica da expedição, no naufrágio de um iate que levaria o material para Fortaleza (LOPES, 1996; PORTO ALEGRE, 2003).

A proposta do presente artigo é analisar a Comissão Científica de Exploração fora de sua "forma consagrada", reconhecendo neste empreendido político-científico algo que vá além de uma arenga entre avaliações sobre a natureza brasílica — ou um arroubo romântico que lograria aos nossos naturalistas a vantagem de filhos deste solo, e assim saberem mais e melhor das coisas da nossa terra, pois "um país, para ser dono de si, precisava ter fala própria" (RAMOS, 2012, p. 10). Muitas vezes referida como uma expedição malfadada, o fato é que a Comissão Científica contribuiu decisivamente no desenvolvimento da ciência nacional, ao aliar o levantamento das condições materiais de regiões pouco exploradas do país e contribuir com o movimento de "mobilização do mundo" promovido pelas ciências naturais no período moderno, em que o conhecimento, a nomeação e a organização esquemática da natureza conferiam poder e influência nas disputas nacionais por novos territórios, produtos e mercados em plena era industrial.

Nesse sentido, busco tratar aqui a expedição às províncias do Norte como um projeto político-científico, a partir das percepções e falas produzidas sobre a Comissão na imprensa, na correspondência e em outros escritos dos naturalistas-expedicionários. Meu intuito não é encontrar novos fechos ou definições sobre a Comissão e o seu legado, e sim contribuir com novas possibilidades de tratamento interpretativo de um fazer científico feito de arranques, expectativas, conflitos e descontinuidades.

\section{Uma expedição brasileira: (in)utilidades e interesses}

As primeiras críticas ao projeto da Comissão Científica surgiram menos de seis meses após sua proposição. Uma das matérias de capa do Diário do Rio de Janeiro intitulava-se “A Comissão Exploradora e o Ceará", fazendo considerações sobre as instruções de viagem redigidas por Cândido Batista de Oliveira, que indicavam a província do Ceará como destino da expedição. Apesar de louvar a "inteligência tão vasta quanto esclarecida" de Oliveira, então diretor do Jardim Botânico (1851-1859) e senador pela província do Ceará (1849-1865) — ressaltando, com ironia, este representante vitalício de uma província "que tão espontaneamente 
o elegeu para advogar (...) a sua causa e os seus interesses" ${ }^{2}$-, a matéria questiona o artigo 14 das instruções, que coloca como medida para combater as secas na região a sondagem para a instalação de poços artesianos.

Ora, fontes artesianas atenderiam, segundo a matéria, apenas o fornecimento de água para a população e os animais, desnecessárias numa província cujos povoados quase todos estão situados à margem dos rios, bastando cavar "dois ou três palmos de areia para rebentarem veias abundantes e inesgotáveis de água doce e salubre.” O flagelo da seca só seria aplacado com a “introdução de uma grande massa de água corrente e perene (...), [qu]e entretenha a umidade atmosférica, melhoramento que só por si bastará para conservação da verdura das matas, e por conseguinte para a extinção das secas". A melhor solução seria canalizar o rio São Francisco para encher o leito do rio Jaguaribe. Afinal, o autor diz esperar que o "tão ilustre brasileiro a quem nos referimos não poupará nenhum dos imensos recursos de que dispôs para livrar a província que tão dignamente representa no parlamento, de um flagelo assustador que ameaça tragá-la nas voragens de um abismo, qual é a seca". ${ }^{3}$

Esse desacerto enseja uma análise mais acurada de um dos pontos mais debatidos sobre a Comissão Científica: a escolha do Ceará como ponto de partida, e posteriormente a única província a ser totalmente percorrida pelos comissionados. Capanema arrolou entre os objetos comprados para a execução da viagem "uma canoa portátil de goma elástica" importada dos Estados Unidos para o exame de rios e lagoas nos lugares onde não houver embarcações, ${ }^{4}$ o que denota a possibilidade de haver um outro roteiro. Dentre as províncias do Norte (correspondente hoje ao Norte e Nordeste brasileiros) palmilhadas por viajantes estrangeiros, a preferência pelas regiões amazônicas era então candente pela profusão de espécies visíveis quanto por tudo que as densas matas poderiam encobrir, desde tribos edênicas até monumentos de civilizações antigas, que até nossos dias são encontrados sob camadas de vegetação, em escavações ou mesmo submersos. A proposta de Lagos e o relatório de Capanema (1857) informando o Instituto Histórico sobre o andamento dos preparativos da viagem ${ }^{5}$ referem-se às "províncias menos conhecidas" como destino da expedição, assim como as cartas trocadas entre Capanema, Raja Gabaglia e Gonçalves Dias, que discutem as dificuldades de ir ao "interior" ou ao "sertão". Antonio José da Serra Gomes, adido do Brasil em Lisboa, indaga Dias se "a comissão do

\footnotetext{
${ }^{2}$ Os senadores nesse período eram escolhidos pelo imperador a partir de uma lista tríplice, com candidatos eleitos nas províncias por votação indireta e majoritária. Para o cargo, que era vitalício, somente podiam ser candidatos cidadãos natos ou naturalizados com idade mínima de 40 anos e rendimento anual acima dos 800 mil réis.

3 “A Comissão Exploradora e o Ceará". Diário do Rio de Janeiro, 27 de novembro de 1856, p. 1. Acervo da Biblioteca Nacional.

${ }^{4}$ Relatório do Sr. Dr. Capanema lido pelo Sr. A. A. P. Coruja. Revista do IHGB, tomo XX, 1857, p. 570-571, p. 65.

${ }^{5}$ Relatório do Sr. Dr. Capanema lido pelo Sr. A. A. P. Coruja. Op. cit., p. 63.
} 
Amazonas contará o meu amigo entre os seus", ${ }^{6}$ o que evidencia as incertezas em torno do destino dos comissionados e uma atração imediata que as matas amazônicas exerciam.

Na documentação sobre a expedição, há um relatório apresentado à Assembleia Geral Legislativa em princípios de 1857 pelo então secretário de Estado dos Negócios do Império, Luís Pedreira de Couto Ferraz, entusiasta da empreitada, apontando o Ceará como ponto inicial dos trabalhos, mas sem indicações do que teria motivado tal escolha (BRAGA, 1962, p. 36). A primeira alusão específica ao Ceará entre os naturalistas é feita em 3 de setembro de $1857,{ }^{7}$ o que ainda assim parece deveras vago para um empreendimento que pretendia arrolar tantas descobertas e primazias. A alusão é feita quando Gonçalves Dias, como era seu costume, pede notícias da filha e da esposa de Capanema. "Como vão a minha afilhada e a Comadre? A última sem dúvida satisfeita em ir até ao Ceará [sic.]”. O trivial da circunstância pode indicar pouco caso em relação ao local, ou que esta fosse uma escolha a ser revertida, se nos fiarmos na posição de que Capanema pretendia aliciar Dias a fazer uma "Comissãozinha paralela" (BRAGA, 1962, p. 51) Mas para isso teríamos que colocar igualmente em suspeição Francisco Freire Alemão, que acumulava os cargos de presidente da Comissão Científica e chefe da Seção Botânica. Um dia antes de embarcar no vapor Tocantins, Freire Alemão escreve a Carl von Martius, dizendo: "Parece que a primeira província a explorar-se será o Ceará" [grifo meu]. ${ }^{8}$ Como alguém que, em suas próprias palavras, está prestes de uma grande viagem exploratória não sabe (ou não quer dizer) seu itinerário?

Talvez por isso as instruções de viagem das seções Botânica, Geológica, Zoológica e Narrativa de Viagem tenham um caráter mais generalista, na medida em que aquelas orientações de prospecção poderiam ser aplicadas a qualquer região do país. As instruções da Seção Astronômica são as únicas que se referem nomeadamente ao Ceará. Cândido Batista de Oliveira e Manuel de Araújo Porto Alegre redigiram as instruções da Seção Astronômica e Geográfica e da Seção Etnográfica e Narrativa de Viagem, respectivamente, enquanto seus chefes estavam na Europa em busca de materiais para a viagem. Já no proêmio dos Trabalhos da Comissão Científica de Exploração, Gonçalves Dias relata que, embora tendo sido logo escolhidos os chefes das cinco seções, não foram designadas que províncias seriam percorridas e de onde partiria a expedição, a ponto de ele e Gabaglia terem encomendado equipamentos para a dupla eventualidade de uma expedição por terra e por água.

\footnotetext{
${ }^{6}$ Carta de [Antonio José da] Serra Gomes a Antonio Gonçalves Dias, Lisboa, 28/01/1857. In Anais da Biblioteca Nacional (Correspondência passiva de Gonçalves Dias), vol. 91, 1971, p. 102.

${ }^{7}$ Carta de Antonio Gonçalves Dias a Guilherme Capanema, Paris, 03/09/1857. In Anais da Biblioteca Nacional (Correspondência ativa de Gonçalves Dias), vol. 84, 1964, p. 228.

${ }^{8}$ Carta ao Doutor Martius, em 25 de janeiro de 1859. In: DAMASCENO, Darcy e CUNHA, Waldir da. Os manuscritos do botânico Freire Alemão, catálogo e transcrição. Rio de Janeiro: Divisão de Publicações e Divulgação da Biblioteca Nacional, 1964, p. 151.
} 
Percebe-se também um clima de expectativa se formando na comunidade internacional, diante da possibilidade de uma expedição ao interior, desafiadora mas rica em possibilidades. Em carta a Capanema, de 5 de maio de 1857, Gonçalves Dias, que se encontrava em Dresden na preparação da compra dos materiais da Comissão, comenta:

Só te devo dizer que o Sturtz com o seu costumado abelhudismo, pediu uns apontamentos relativos à tua comissão ao Dr. Gustav Ienzsch, de Dresde, que neste momento acabo de ler. Não sei que valor tem isso, mas o moço fez o que the pediu o Sturtz, e um pouco vexado de semelhante incumbência. ${ }^{9}$

Gonçalves Dias faz referência na carta a João Diogo Sturz, ${ }^{10}$ cônsul geral do Brasil na Prússia. O círculo de amizades que Dias buscava cultivar na Europa permitiu-lhe tomar conhecimento das indagações de Sturz sobre a Comissão, que entretanto estavam longe de um mero "abelhudismo". Sturz encabeçava um grupo de empresários que tentava obter, desde 1837 , a concessão para explorar a navegação a vapor nos rios Amazonas, Tocantins, Solimões, Negro e seus afluentes. O projeto apresentado à Câmara dos Deputados previa a introdução de linhas regulares de vapores na região, solicitando em contrapartida uma série de vantagens, como o privilégio de exclusividade da navegação por 40 anos, isenção de impostos de importação sobre quaisquer compras realizadas fora do País para manutenção da atividade e "a doação de todas as minas de carvão ou qualquer outro mineral que fossem descobertos nos primeiros anos de atividade" (GREGÓRIO, 2009, p. 190-191, grifo meu).

Mesmo com a incerteza em relação ao projeto, que levaria mais de duas décadas para ser finalmente rejeitado pelo Senado, em 1864, fica clara a intenção de Sturz de se cercar do maior número de informações sobre os estudos geológicos a serem feitos pela Comissão Científica. Mesmo sem sabermos o teor dos apontamentos "encomendados" por Sturz (que poderia muito bem tê-los pedido diretamente à Capanema, já que ambos eram servidores do Império), tais informações poderiam levar a empresa a descobrir jazidas de carvão próximas à região amazônica antes do governo. Como a Seção Geológica também se ocupava da navegabilidade dos rios, poder-se-ia mesmo introduzir linhas a vapor no Ceará — estabelecendo de antemão nos contratos de concessão vantagens de exploração de minerais. Nas discussões na Câmara e no Senado, havia os que argumentavam que tais privilégios na navegação a vapor eram essenciais

\footnotetext{
${ }^{9}$ Carta de Antonio Gonçalves Dias a Guilherme Capanema. Dresde[n], 05/05/1857. In Anais da Biblioteca Nacional (Correspondência ativa de Gonçalves Dias), vol. 84, 1964, p. 219.

${ }^{10}$ Nascido na Prússia em 1800, naturalizou-se brasileiro na década de 1840 e exerceu intensa atividade empresarial no País. Autor de alguns textos sobre a introdução de máquinas no Brasil e sobre a economia nacional, foi um dos sócios da Sociedade Auxiliadora da Indústria Nacional, nas décadas de 1830 e 1840, e do Instituto Histórico e Geográfico Brasileiro. Foi comissário do Império na exposição geral da indústria realizada em Londres, em 1851.
} 
para o estabelecimento da atividade em regiões de difícil acesso. Por outro lado, a busca de informações "por fora" nos indica que o temor, professado por alguns setores do Legislativo, de que "um estrangeiro" como Sturz conseguisse tantas vantagens a ponto de fazer predominar interesses externos ao Império numa área estratégica não era de todo infundado.

$\mathrm{Na}$ imprensa pululam manifestações acerca da utilidade ou desvantagem desse tipo de exploração, com destaque ora para o engrandecimento da nação pelo conhecimento, ora para os "imensos recursos" que mobilizam - e que melhor seriam aproveitados em outras necessidades do país. Para o bem ou para o mal, a Comissão Científica figura como referência nestas questões. Novamente o Diário do Rio de Janeiro alerta sobre a inutilidade de enviar uma outra comissão para explorar o rio Tibagi, no Paraná, por já se conhecer de antemão suas inúmeras corredeiras e a pouca profundidade de seu leito (o que inviabilizaria fazer o trajeto em canoas), bem como o risco de expor os viajantes a caminhos com poucos recursos, em que é preciso "carregar os objetos em costas de animais, por cujo frete se pede grande quantia”.

Destaca, porém, o papel aglutinador que se esperava da Comissão Científica, considerada mais proveitosa do que pequenas explorações. "Pois que o governo há de auxiliar essa comissão e lhe há de fornecer dinheiros, pois que essa comissão científica há de fazer aquilo que as comissões exploradoras foram encarregadas, é claro a todas as luzes o que deixamos dito". 11 Mesmo assim, denota-se no texto uma discussão há muito superada, em que o imperativo da exploração do interior já se sobrepõe a perigos e despesas, numa tradição iniciada com a ambiciosa (e trágica) expedição La Condamine (1735-1745), passando pelas viagens científicas de Alexander von Humboldt (1799-1804) e a já citada de Martius e Spix (1817-1820) — para ficarmos apenas em explorações na América do Sul.

Estes vastos conteúdos seriam conhecidos não por meio de linhas finas sobre um papel em branco, mas por representações verbais que por sua vez são condensadas em nomenclaturas ou por meio de grades rotuladas nas quais as entidades são inseridas. A totalidade finita destas representações ou categorias constitui um "mapeamento", não só de linhas costeiras ou rios, mas de cada polegada quadrada, ou mesmo cúbica, da superfície terrestre (PRATT, 1999, p. 64).

Um mês antes, o Correio Mercantil iria na contramão, conclamando os cidadãos na festa do 7 de setembro a estimar e prezar o que é da pátria. Pátria esta que surpreende os que aqui vêm estudar nossos usos, costumes e grau de adiantamento, desvanecendo a reputação inferior pintada no estrangeiro. $\mathrm{O}$ artigo referia-se à recente partida no porto do Rio de Janeiro da fragata

\footnotetext{
11 “A opinião e o governo e as explorações dos rios interiores". Diário do Rio de Janeiro, 23 de outubro de 1857, p. 1. Acervo da Biblioteca Nacional.
} 
Novara, trazendo os membros da comissão austríaca que fariam uma viagem de circumnavegação pelo globo, considerada a última grande expedição científica global do século XIX. Informa que a fragata voltaria ao Rio antes de aportar definitivamente na Europa, a fim de fazer permutas científicas com a nossa Científica, que a este tempo já haveria retornado à Corte. A comparação tanto das iniciativas quanto dos dois países reforça o valor de uma exploração em nossas províncias interiores.

Este exemplo, dado por um governo absoluto, e que, como diz o vienense Saphir, está atrasado de um século, deve mostrar que não foi um plano absurdo o de mandar ao nosso interior uma Comissão Científica dirigida pelo sábio Dr. Freire Alemão. Se a Áustria colherá disso não pequenas vantagens, por que não tirará o Brasil igual ou maior proveito de uma expedição do mesmo gênero? ${ }^{12}$

Nos dois artigos evidencia-se uma compreensão extremada do fazer científico; por um subestimado pela "inutilidade" diante de outras urgências, e por outro exagerando a capacidade de a comissão, por si só, equiparar o Brasil às demais nações civilizadas. Não se levava em conta que o historiador natural era guiado por demandas distintas de conquistadores e comerciantes embora várias vezes tenha se associado a estes para alcançar regiões mais remotas e atuado como agente da expansão imperialista. Sua área de atuação era precisamente o sertão; e os conteúdos dessas massas de terra a água, cuja pujança e diversidade se impunham como verdadeiras barreiras naturais, quase intransponíveis, seu objeto de estudo. No meio de densas florestas ou entocada em áreas de caatinga poderia muito bem haver eldorados ou vestígios de civilizações tão antigas quanto os astecas, incas e maias, das quais os indígenas seriam "descendentes degenerados". Ou, como destacara Manoel Ferreira Lagos em seu argumento a favor da Científica, a descoberta de uma simples folha ou animal que abrisse novos mercados ou rivalizasse com os existentes era justificativa mais que suficiente para o investimento em viagens científicas.

Mesmo em condições ideais de financiamento, equipamento e pessoal, era impossível prever todos os percalços de um percurso. Ou, sendo a viagem bem-sucedida, garantir a descoberta de conhecimentos e produtos que pudessem ser utilizados a curto e médio prazo. Para Karen Lisboa, mais do que registrar a observação de uma cultura declarada estrangeira, aquilo que o viajante traz em seu retorno (coleções, amostras, diários, desenhos) nos oferece, antes, amplas evidências da cultura do indivíduo. "Portanto, ao mesmo tempo em que o viajante fala do lugar visitado, [o autor-viajante] reelabora o seu próprio lugar de origem, permanecendo em

\footnotetext{
12 "Páginas menores. 7 de setembro". Correio Mercantil, 7 de setembro de 1857,p. 1. Acervo da Biblioteca Nacional.
} 
constante diálogo com as suas referências, que podem ser revistas, negadas ou reiteradas" (LISBOA, 1997, p. 47).

\section{Tensões e limites do fazer científico nos trópicos}

O projeto do IHGB de fazer conhecer as regiões mais distantes do Império recémformado seguia uma tradição de pesquisa e formação de inventários estabelecida desde o século XVIII. Ciosa em descobrir artefatos, técnicas, plantas ou minerais que reforçassem o erário real, a metrópole portuguesa, com o apoio da Universidade de Coimbra, tomou para si a incumbência de formar exploradores e naturalistas luso-brasileiros e enviá-los para devassar suas possessões coloniais. Os vassalos ilustrados da Coroa, além de enviar produtos que pudessem dinamizar as trocas comerciais entre o império e o ultramar, deveriam remeter memórias, relatórios e desenhos de tudo o que vissem e ouvissem em suas viagens. “(...) A produção de inventários e a circulação de notícias permitiam tornar mais palpável a idéia de um império colonial, composto por possessões que aos poucos se integravam e tornavam-se interdependentes" (RAMINELLI, 2008, p. 214). ${ }^{13}$

É preciso, contudo, considerar certos limites no uso da ciência como braço intelectual do desenvolvimento do Estado. O que se observa na trajetória das ciências no Brasil, mesmo com os esforços empregados num reformismo científico desde finais do Setecentos, é que o investimento na formação de vassalos ilustrados, exploração do interior das colônias e divulgação de conhecimentos úteis não impediu que a constituição de redes de informação científica esbarrassem em entraves burocráticos, na influência ainda forte do catolicismo sobre o conhecimento, que conferia "à religião um caráter natural e à Natureza, um sentido religioso", 14 sem falar em certas tradições políticas e culturais, baseadas em relações de proteção e favores. Assim, "sem auditório capacitado para captas as mensagens de persuasão científica, sem estarem assegurados os mecanismos de difusão e popularização dos sucessos e achados, o trabalho dos cientistas perdia oportunidades de consolidação." 15

\footnotetext{
${ }^{13}$ Em contrapartida a esse movimento de vassalos ilustrados pelas possessões ultramarinas, os governadores do Ceará e do Grão-Pará recebem, em 2 de junho de 1800, um ofício do ministro de Estado Rodrigo de Souza Coutinho, futuro conde de Linhares, alertando sobre a presença perigosa de um tal "barão de Humboldt", que andava a esquadrinhar os domínios portugueses na América, "e recomendando para ele e qualquer outro, que não estivesse autorizado a pesquisar, vigilância severa e mesmo prisão irrecorrível." COLARES, Otacílio. Crônicas da Fortaleza e do Siará Grande. Fortaleza: Edições UFC/ Prefeitura Municipal de Fortaleza, 1980, p. 23.

${ }^{14}$ COSTA, Alexandre da Cunha apud NEVES, Guilherme Pereira das. "Natureza, ciência e política no mundo luso brasileiro de inícios do século XIX. In: KURY, Lorelai e GESTEIRA, Heloísa (orgs.). Ensaios de história das ciências no Brasil: das Luzes à nação independente. Rio de Janeiro: Ed UERJ, 2012, p. 288.

${ }^{15}$ CARDOSO, José Luís apud NEVES, Guilherme Pereira das. Op. cit., p. 289.
} 
Podemos pensar, por exemplo, em algumas "situações obscuras e de peripécias rocambolescas", levantadas por Guilherme das Neves. Desde o arquivamento e extravio dos trabalhos de Alexandre Rodrigues Ferreira e do frei José Mariano da Conceição Veloso, que inspirara Freire Alemão — pilhados pelos franceses durante as invasões napoleônicas e publicados tempos depois, quando suas contribuições já haviam sido superadas por outros estudiosos — até as contradições no tocante às publicações da Tipografia do Arco do Cego, incumbida da divulgação do conhecimento sobre a vida e a natureza no Brasil. Dirigida por frei Veloso de 1799 a 1805, e em detrimento de sua obra magna, a Flora fluminensis, Veloso optou por atuar como editor de obras e folhetos de filosofia natural a serem enviados à colônia. Estas obras de utilidade não só eram "pouco representativas em termos de conhecimento", como também "nunca eram adquiridos e, quando distribuídos gratuitamente, nem mesmo lidos ou aplicados eram pelos principais destinatários, os fazendeiros do Brasil." (NEVES, 2002, p. 285286).

A tradição instrumental herdada da monarquia lusitana ainda pesava na estrutura do Império - e, por conseguinte, sobre nossos naturalistas, que dependiam do seu financiamento. A presença desses naturalistas em várias instituições científicas do Império pode ser um indício não só de um projeto unificado, mas também da dificuldade de manutenção de quadros, tanto em relação a número de profissionais quanto de recursos, obrigando-os a atuar em mais de uma frente para complementar a renda. A comunidade de naturalistas emergente no Brasil também não era tão coesa quando a fala de Lagos tenta colocar, dividida em interesses e ideias científicas distintas, quando não francamente conflitantes.

Comparativamente ao período anterior, as Ciências Naturais [em meados do século XIX], de modo geral, não tiveram presença marcante nesse projeto que consolidou a economia agrária, dependente e escravocrata brasileira. A outra "face da moeda" desse projeto, de institucionalização das Ciências Naturais no país, que se destaca foram as iniciativas da emergente comunidade científica que disputou, com relativo êxito, apoio político e mecenato imperial para cada uma de suas ações e de seus diferentes interesses (LOPES, 1997, p. 325).

Acredito que essa posição das ciências naturais no período seja menos de ausência do que uma dificuldade em colocar as projeções em prática, devidos às circunstâncias do país, interpenetrada por tradições e ideologias. Isso pode explicar em parte o desapreço que a expedição aos sertões cearenses sofreu. Um exemplo disso são as desavenças, ocorridas ainda durante a fase de preparação da Comissão Científica, entre o chefe da Seção Geológica e Pedro de Araújo Lima, marquês de Olinda, então chefe do gabinete imperial e ministro do Império. Renato Braga atribui, apoiado na correspondência entre Capanema e Gonçalves Dias, o atraso na 
compra de materiais para a viagem na Europa e a postergação do retorno de Dias e Gabaglia para o início da Comissão a uma orientação do próprio Capanema, motivado por questões políticas e pessoais com o ministro. Além das reservas contra o velho regente, Capanema teria tomado as dores do cunhado, Araújo Porto-Alegre, quando este dirigia a Escola de Belas Artes. Olinda teria nomeado para a cadeira de Pintura Histórica "um substituto de pouca habilidade artística, grande, porém, nas artes de alcovitice”, desautorizando Porto-Alegre, que se demitiu do cargo. A história é relatada por Capanema a Dias, ressaltando ao amigo ser uma imprudência ir para o sertão enquanto Olinda fosse ministro.

Ora supõe tu que o velho Marquês quando estivermos lá no interior se lembre de repente que os cofres públicos não suportam tal expedição e sem mais nem mais nos suspenda? Ou que al[guns] caretas, armados de [ilegível] saibam gan[har os] bons afetos do Exmo. Presidente do Conselho e que o Excelentíssimo descubra que nós somos insuficientes para dar conta da mão, e nos ordene aceitar uns tantos inconvivíveis estúpidos, ajudantes, companheiros ou chefes? Etc. etc. etc. Não crês que quem salta por cima de uma lei para proteger um afilhado seja capaz de pular por cima de nós? E depois do exemplo citado devemos confiar ao I. [imperador] que por nossa causa certamente não fará questão de gabinete, pois que em nós não está de certo a salvação da pátria. ${ }^{16}$

O que se percebe no trecho acima é que, mesmo com as dúvidas que Capanema levanta, nesta e em outras cartas a Dias, em relação à possibilidade de realizar a expedição tal como foi projetada, diante das restrições de suporte dos cofres públicos e de um número insuficiente de naturalistas empregados, o geólogo quer evitar a todo custo a ingerência de gabinetes políticos sobre a Comissão Científica. O chefe da Seção Geológica consegue defender, simultaneamente, a construção do Estado Imperial e seus interesses, como membro de numa comunidade científica emergente, que malgrado "suas divergências e desacordos, e possivelmente capacidades científicas diferenciadas" (LOPES, 1997, p. 143), procurava se impor numa certa unidade. E também a posição frágil da ciência dentro deste projeto, quando Capanema considera que nem mesmo o imperador, entusiasta de primeira hora da viagem exploratória e seu amigo de infância, entrasse em questão com o ministro Olinda diante da posição baixa da Comissão na lista de prioridades do governo.

Entretanto, uma hipótese plausível é de que a desconfiança de intenções fosse mútua. $\mathrm{Na}$ coleção marquês de Olinda, sob a guarda do IHGB, encontra-se a cópia de cartas de Capanema a Gonçalves Dias, chefe da Seção Etnográfica, compreendidas entre 1858 e 1861, com

\footnotetext{
${ }^{16}$ Carta de Guilherme Capanema a Antonio Gonçalves Dias, Rio de Janeiro, 12/11/1857. In Anais da Biblioteca Nacional (Correspondência passiva de Gonçalves Dias), vol. 84, 1964, p. 157.
} 
comentários dos comissionados sobre a organização e os rumos da Comissão Científica. O manuscrito é atribuído pela instituição a um funcionário da Secretaria do Estado do Ministério do Império. Em carta a Capanema, de 15 de maio de $1857,{ }^{17}$ Gonçalves Dias havia alertado o amigo que as cartas dele chegavam à Alemanha abertas, e que o mesmo havia acontecido com a correspondência de Gabaglia. A suspeita era de que a violação ocorresse na Secretaria de Estado de Negócios Estrangeiros (onde Dias e Ferreira Lagos tinham cargos de oficiais) ou na Secretaria de Estado dos Negócios do Império, de onde eram despachados cartas e ofícios para a Europa. A carta segue dando conta de atrasos de meses no recebimento de ofícios do Brasil (o que teria, segundo Dias, atrasado a compra de material para a Comissão).

O gabinete de Olinda é dissolvido em dezembro de 1858, e Capanema pode finalmente desfazer os entraves para a viagem. O grande temor de Capanema se realiza, porém, na gestão do ministro seguinte, Ângelo Moniz da Silva Ferraz (1859-1861), que também acumula a presidência do Conselho de Ministros. A nova tabela de vencimentos da Comissão, promulgada pela Lei de Orçamento n. 114, de 27 de setembro de 1860, trazia graves cortes previstos para o biênio 1861-1862. A verba passara de 140 para 130 contos de réis, incidindo sobre quantitativo de pessoal e outras despesas. O vencimento dos chefes de seção foi diminuído de 7:200\$000 para 5:400\$000 anuais (BRAGA, 1962, p. 75). A comunicação, porém, segundo Gonçalves Dias, só teria chegado ao conhecimento de Freire Alemão em 9 de janeiro do ano seguinte, quando o presidente da Científica encontrava-se em Sobral e vários gastos já haviam sido feitos ou empenhados. Em resposta, o governo imperial, em correspondência de 19 de fevereiro de 1861, determinou que a nova tabela só passasse a valer de fevereiro em diante, o que não evitou o comprometimento dos trabalhos, planejados a partir de um determinado orçamento e número de ajudantes. Isso sem falar nas seções que já enfrentavam limitações desde o início, como a Seção Astronômica, que desde o início da expedição só contara com metade do número de adjuntos requisitados e não teve atendida a solicitação de uma canhoneira para o levantamento dos dados hidrográficos da província (DIAS, 1962, p. 240-241).

A viagem exploratória podia contar com o apoio de Pedro II, mas uma burocracia imperial, por mais centralizada, é composta por diversas demandas e interesses, dos mais relevantes para construir um projeto de Estado aos mais iníquos em termos de inimizades e malquerenças. A vigilância dos passos de membros da Comissão via espionagem interna indica um movimento na querela pessoal entre Capanema e Olinda, tanto que a "vingança" não tardaria. Talvez "inspirado" pelos comentários de Capanema sobre a "nossa excursão tupi, donde poderei

\footnotetext{
${ }^{17}$ Carta de Antonio Gonçalves Dias a Guilherme Capanema, Dresde, 05/05/18597. In Anais da Biblioteca Nacional (Correspondência ativa de Gonçalves Dias), vol. 84, 1964, p. 218 a 221.
} 
trazer alguma infernal galiqueira [doença sifilítica] pelas emanações de você já sabe", ${ }^{18}$ ao voltar ao cargo de ministro dos Negócios do Império em 1862, o marquês de Olinda inicia uma investigação para apurar "escândalos e desmandos provocados por Guilherme Schüch Capanema". O resultado desta investigação encontra-se na forma de um documento manuscrito ${ }^{19}$ (que também se encontra na Coleção Marquês de Olinda), cuja letra é atribuída pelo IHGB a Tomás Xavier Garcia de Albuquerque Júnior, a mesma letra com que foram copiadas as cartas de Capanema.

Intitulada "Epílogo da crônica de parte dos membros da Comissão Científica, durante sua estada na cidade de Fortaleza, capital da província do Ceará”, a peça relata que, enquanto Capanema ainda estava a caminho da província, os demais companheiros "comportaram-se com a precisa dignidade". "Logo, porém, que ele se lhes reuniu, apossou-se do deplorável Gonçalves Dias, que de mais tempo se deixara fascinar e dirigir por ele, e com estes dois foram mais outros para uma casa onde Capanema estabeleceu logo uma orgia uma orgia continuada, escandalosa e pública". ${ }^{20} \mathrm{O}$ alvo principal dos ataques é o amigo de infância do imperador. Os meses de permanência em Fortaleza, justificados pela Comissão diante da impossibilidade de adentrar o sertão em período de chuva, foram segundo o Investigador um período de sevícias, embriaguez e achincalhe públicos, em que seria impossível a realização de qualquer trabalho científico.

Testemunhas davam conta de festas com prostitutas, o abandono do vestuário da Corte por "calças largas de enfiar chamadas = bombachas =, de jaquetas, chinelos e chapéus de palha". E uma vez trajados como qualquer sertanejo, dar-se-iam a provocar e dirigir gracejos atrevidos e impudicos às moças e senhoras à janela, que já cuidavam de fechar-se assim que os avistavam. "Refere-se o dito de uma senhora para caracterizá-los: 'Eu não sei (dizia ela) por que o Imperador não mandou para cá melhores moleques' (grifo no original).” Capanema e Dias teriam tomado para si duas irmãs "solteiras, posto que pobres, muito recatadas, e tidas em bom conceito". Enganando o velho pai das moças com promessas de casamento, Capanema corrompeu-as e chegou ao desplante de instalar as irmãs e o pai num sítio afastado. Nesse ponto

\footnotetext{
${ }^{18}$ Carta de Guilherme Capanema a Antonio Gonçalves Dias. Praia Grande, 12/01/1858. In Anais da Biblioteca Nacional (Correspondência passiva de Gonçalves Dias), vol. 84, 1964, p. 174.

19 Renato Braga atribui este relato a Francisco Freire Alemão, pelo fato de este documento se encontrar, segundo ele, nos documentos do botânico doados à Biblioteca Nacional. Braga chega a creditar grande confiabilidade ao "Epílogo..." por tal atribuição. Mas em busca no site da Biblioteca Nacional, encontramos este documento na Coleção Gonçalves Dias, na parte Documentos Biográficos. O fato de um documento estar numa determinada coleção não implica que este tenha sido produzido ou manuseado pela pessoa que dá nome à coleção. Não encontramos, portanto, evidências que corroborem tal autoria. O documento (ou cópia) encontrado no IHGB (e no qual baseamos a presente análise) vem assinado como "O Investigador" e não guarda qualquer semelhança nem com a letra de Francisco Freire Alemão no manuscrito do diário de viagem que redigiu no transcurso da Comissão nem com a do período em questão, já bastante trêmula por conta do derrame que o acometeu.

20 "Epílogo da crônica de parte dos membros da Comissão Científica, durante sua estada na cidade de Fortaleza, capital da província do Ceará”. Rio de Janeiro, 14 de setembro de 1865. Ms., IHGB, Lata 208. Doc. 29, Coleção Marquês de Olinda, p. 1.
} 
nem mesmo seu melhor amigo teria ficado do seu lado: "Dias reagiu contra o Mefistófeles que o arrastou aos deboches e à perdição; separou-se dele e de todos os da Comissão, foi para o Maranhão e daí para o Amazonas". ${ }^{21}$

O crime maior, no entanto, teria sido o naufrágio, diante das circunstâncias, premeditado e proposital do iate Palpite, como forma de Capanema encobrir a ausência de estudos e trabalhos enquanto mantinha no Ceará uma vida “engolfada em tão asqueroso lodaçal de vícios". O relatório dá conta de que, na volta do interior, Capanema teria fretado um barco para levar à Fortaleza os preciosos livros e equipamentos necessários aos trabalhos da sua Comissão, "mas ad cautelum deixou-se ficar em terra". O Investigador alega que a "tragédia" teria se dado no decurso de uma viagem em rio manso, com correnteza a favor e de tal forma que as águas se contentaram em levar apenas os caixotes e canastras da expedição, não tendo perecido nenhum dos tripulantes, que permaneceram com seus haveres. Teriam ficado, apenas, "por esquecimento", as anotações que serviram de base para os Ziguezagues, publicadas por Capanema sob pseudônimo no Diário do Rio Janeiro entre 1860 e 1862.

Indagar a veracidade de tal relatório seria tarefa infinda e insolúvel. Interessa-me, antes, a forma como o documento procura dar ao leitor garantias de sua legitimidade, fiando o relato em testemunhos de "pessoas conspícuas e respeitáveis", que poderiam ser facilmente chamadas a confirmar tais fatos:

Em Pernambuco existe o Dr. Silveira de Souza que os observou com tédio e indignação. Nesta Corte existem Senadores que, se quiserem, as poderão referir em confiança. O Capitão do Estado Maior da $2^{\text {a }}$ Classe, atual Comandante da Fortaleza da Lage, aí está, que sabe com toda individualidade dessas ocorrências crapulosas: conhece Rufo e sua família (...).

O Capitão Luiz Taumaturgo da Guerra Machado, que veio por doente do exército do Sul, e para ele está em vésperas de voltar; e seu sobrinho Antônio Pio Machado, que esteve na Diretoria da Colônia do Mucuripe, e está para partir para a do Assumguy na Província do Paraná, ambos naturais do Ceará (...) testemunharam e referem todos os fatos narrados. ${ }^{22}$

Apesar disso, fica claro pela composição do texto que o alvo principal é o barão de Capanema, o que reforça que a produção deste relatório tenha partido do gabinete de Olinda. Com exceção de Gonçalves Dias, amigo próximo e compadre de Capanema, nenhum outro membro da Comissão que o teria acompanhado nas orgias e farras é citado nominalmente. Mesmo aquele é "eximido" ao se revoltar contra as mancebias e engodos à família Rufo, tendo "se separado dele e de todos da Comissão" - quando na verdade Gonçalves Dias só partiu da

21 "Epílogo da crônica de parte dos membros da Comissão Científica...”. Op. cit., p. 2.

22 "Epílogo da crônica de parte dos membros da Comissão Científica...". Op. cit., p. 3. 
província em agosto de 1860, depois de seguir com Capanema para o interior. O tom do escrito também passa longe da frieza conscienciosa que se espera de um relatório, com comentários e tiradas irônicos: "Na volta, comprou um barquito velho e desconjuntado chamado $=$ Palpite $=$ (que palpite!!!)". ${ }^{23}$

\section{Conclusão}

Estas breves indagações em torno da concepção e da recepção da Comissão Científica de Exploração acabam por reverberar algo mais amplo: as tensões entre instituições científicas e o governo imperial daquele período, permeadas por demandas diretamente proporcionais às descontinuidades nos projetos. iniciativas como a Comissão Científica de Exploração, permeada por demandas que se modificavam rapidamente, irregularidades no orçamento e comparações com o que se realizava no estrangeiro, fazendo-se a ressalva de que estas contavam com maior tradição e aporte financeiro regular. É por esta chave que devemos ler a parte final do Proêmio dos Trabalhos da Comissão Científica de Exploração, onde Gonçalves Dias inverte o sentido da comparação para justificar aquele "leve bosquejo" da história da expedição, já que o mais importante, o estudo das coleções trazidas e seus desdobramentos, "é negócio de meditação e de tempo".

Uma comissão idêntica, organizada pelo governo austríaco, e que há anos esteve aqui no Rio de Janeiro, na fragata Novara, viajando com outras comodidades, que não teve a Comissão brasileira, e hoje de volta à Europa, habilitada e dispondo de outros recursos, que estamos muito longe de possuir, para a mais pronta execução e apresentação dos seus trabalhos, pediu para isso quatro anos: e esse prazo mínimo, reclamado pela Seção Etnográfica, a cargo do ilustre Sr. Dr. Carlos Schertzer, a ninguém pareceu excessivo (DIAS, 1962, p. 163).

O tempo da ciência parece então desconectado do que ficou conhecido como tempo saquarema, em que um colonialismo cidadão, baseado na economia agrária, na escravidão e na dependência das nações civilizadas, dava ao Segundo Reinado, embora caracterizado como um período de ruptura e criação de um tempo novo, o sentido de continuidade de um projeto político conservador, neutralizando as forças sociais e políticas progressistas e anulando as insurreições populares nas províncias (MATTOS, 1987, p. 80-86). Nessa conjuntura intrincada e por vezes de movimentos paradoxais, Maria Margaret Lopes chega a afirmar que, embora o reinado de Pedro

23 "Epílogo da crônica de parte dos membros da Comissão Científica...". Op. cit., p. 2. 
II tenha sido propício para a consolidação das Ciências Naturais, estas, de modo geral, não tiveram a mesma centralidade no projeto político e estratégico brasileiro em relação ao período joanino e primeiros anos do Império. A comunidade científica, dividida por diferentes interesses e mesmo por capacidades intelectuais diferenciadas, não teve condições de implantar um projeto consolidado, ficando as iniciativas de cada um desses naturalistas (muitas delas em franca disputa) limitadas pelas vagas do mecenato imperial ou do favorecimento político.

A busca de um protagonismo tanto discursivo quanto explorador, na promoção de expedições como a Comissão Científica de Exploração, encontra sentido no rompimento com a literatura de viagens produzida a partir de associações com parâmetros e valores europeus, bem como no intento de colocar literalmente em campo naturalistas a serviço da nação. Homens que soubessem apreender todos os estímulos e variedade dos trópicos, armados com as mais avançadas técnicas científicas e com o sentimento patriótico que só um "filho da terra" saberia ter. Só assim seria possível integrar regiões temporal e espacialmente distantes, vistas a partir da Corte como vazios a serem alcançados e explorados. Uma exploração que poderia até mesmo "mudar a face do Brasil", ${ }^{24}$ caso se encontrasse no seio dessa natureza luxuriante algum animal, mineral ou planta que nossas vocações científicas, com pés na América e olhos na Europa, inserisse no cabedal de produtos impulsionadores do progresso.

Mas o que os científicos encontrarão nos sertões do Ceará, Piauí e Pernambuco é um país fraturado, tanto que Freire Alemão registra em seu diário a sensação mútua de estarem lidando com estrangeiros. O calor excessivo, o aspecto desolador da paisagem, as atitudes ora amigáveis ora hostis das gentes locais, a própria dificuldade em adentrar o interior diante de tantas barreiras naturais e culturais colocarão continuamente em dúvida a possibilidade de conhecer, de fato, esta parte do país. Não à toa muitos dos viajantes, daqui ou de fora, que se colocaram a tarefa de devassar os sertões brasileiros tiveram suas expectativas malogradas - quando não perderam a razão ou a própria vida. Se a natureza tropical é pouco afeita a enquadramentos, o sentido de integração nacional sonhado por Pedro II ainda hoje é marcado por fissuras e desigualdades.

Some-se a isso a fragilidade do aparato institucional e político do Império que ordenou a exploração da província do Ceará. Mesmo com todos os esforços no incentivo de instituições de pesquisa e sociedades científicas, com a participação do próprio monarca em muitas delas, o fato é que estas ainda são incipientes em relação a seus congêneres europeus - que envolve uma vasta rede de universidades, bibliotecas, agentes coloniais e viajantes espalhados por várias partes do mundo. A utilização de métodos científicos na exploração e catalogação das espécies esbarra não apenas em divergências ideológicas ou estruturais — que serão melhor explicitadas

24 Carta de Antonio Gonçalves Dias a Teófilo, Ceará, 15/02/1859. In Anais da Biblioteca Nacional (Correspondência ativa de Gonçalves Dias), vol. 84, 1964, p. 248.

Oficina do Historiador, Porto Alegre, EDIPUCRS, v. 8, n. 2, jul./dez. 2015, p. 43-59 
no próximo capítulo. O próprio caráter personalista no incentivo dessas instituições e a incompreensão no seio dos meios governamentais das vicissitudes do fazer científico farão com que a Comissão Científica passe de grande iniciativa para os epítetos pouco lisonjeiros com que foi celebrizada, "Comissão Defloradora” ou “Comissão das Borboletas".

\section{Referências bibliográficas}

BRAGA, Renato. História da Comissão Científica de Exploração. Fortaleza: Imprensa Universitária do Ceará, 1962.

DIAS, Antonio Gonçalves. Trabalhos da Comissão Científica de Exploração - Parte Histórica. In BRAGA, Renato. História da Comissão Científica de Exploração. Fortaleza: Imprensa Universitária do Ceará, 1962.

GREGÓRIO, Vitor Marcos. "O progresso a vapor: navegação e desenvolvimento na Amazônia do século XIX”. Nova Economia, Belo Horizonte, n. 19 (1), janeiro-abril de 2009.

LISBOA, Karen Macknow. A Nova Atlântida de Spix e Martius: natureza e civilização na Viagem pelo Brasil (1817-1820). São Paulo, Editora Hucitec, 1997.

LOPES, Maria Margaret. Mais vale um jegue que me carregue que um camelo que me derrube... lá no Ceará. História Ciências, Saúde - Manguinhos. Rio de Janeiro, Fiocruz, volume III, março-junho de 1996.

MATTOS, Ilmar Rohloff de. O tempo saquarema. São Paulo: Hucitec; Brasília, INL, 1987.

NEVES, Guilherme Pereira das. "Natureza, ciência e política no mundo luso brasileiro de inícios do século XIX. In: KURY, Lorelai e GESTEIRA, Heloísa (orgs.). Ensaios de história das ciências no Brasil: das Luzes à nação independente. Rio de Janeiro: Ed UERJ, 2012, p. 281-291.

. O Brasil descobre a pesquisa cientifica: os museus e as ciências naturais no século XIX. São Paulo: Hucitec, 1997.

PORTO ALEGRE, Maria Sylvia. Comissão das Borboletas: a ciência do Império entre o Ceará e a Corte (1856-1867). Fortaleza, Museu do Ceará/ Secult, 2003.

PRATT, Mary Louise. Os Olhos do Império. Relatos de viagem e transculturação. Bauru: EDUSC, 1999.

RAMINELLI, Ronald. Viagens Ultramarinas: monarcas, vassalos e governo a distância. $1^{\mathrm{a}}$ edição, São Paulo, Alameda Editorial, 2008, p. 214.

RAMOS, Francisco Régis Lopes. O Fato e a Fábula: o Ceará na escrita da História. Fortaleza, Expressão Gráfica, 2012. 